\title{
Regulation of Metamorphosis by Environmental Cues and Retinoic Acid Signaling in the Lecithotrophic Larvae of the Starfish Astropecten latespinosus
}

\author{
SHUMPEI YAMAKAWA*, YOSHIAKI MORINO, MASANAO HONDA, AND HIROSHI WADA \\ Graduate School of Life and Environmental Sciences, University of Tsukuba, Tsukuba 305-8572, Japan
}

\begin{abstract}
Common ancestors of starfish (echinoderms) are believed to have planktotrophic larvae, although some species show lecithotrophic larvae, which do not feed before metamorphosis. Furthermore, some lecithotrophic paxillosidan larvae, such as those of Astropecten latespinosus, lack brachiolar arms, the sensory apparatus for the reception of environmental cues in planktotrophic larvae. In this study, we found that the metamorphosis of A. latespinosus was stimulated when larvae were cultured with natural sand from their habitat. We also found that retinoic acid signaling mediated the metamorphosis process upon environmental stimulation, as in planktotrophic larvae. We examined reagent treatments and gene expression analysis by in situ hybridization. Exogenous retinoic acid treatment induced metamorphosis, whereas retinoic acid synthesis inhibitor or antagonist for retinoic acid receptors suppressed metamorphosis. Retinoic acid signalingrelated genes were expressed in juvenile rudiments. In conclusion, we propose that the reception of particular environmental cues is required for the metamorphosis of lecithotrophic larvae.

Many marine invertebrates have biphasic life cycles, with planktonic larval and sessile adult phases (1). Because sessile adults have restricted motility, the settling of larvae in suitable environments during metamorphosis is of critical importance (2). Therefore, planktonic larvae usually possess sensory apparatuses to respond to specific environmental cues (2).
\end{abstract}

Received 17 April 2019; Accepted 23 August 2019; Published online 10 December 2019.

* To whom correspondence should be addressed. Email: shumpei .yamakawa@gmail.com.

Abbreviations: ALDH, aldehyde dehydrogenase; DDBJ, DNA Data Bank of Japan; DEAB, N,N-diethylaminobenzaldehyde; DMSO, dimethyl sulfoxide; hpf, hours post-fertilization; RA, retinoic acid; RALDH, retinoic acid synthesis by retinal dehydrogenase; RAR, retinoic acid receptor; RXR, retinoid X receptor; $\mathrm{RO}, \mathrm{RO} 41-5253$.

Online enhancements: data files.
The ancestors of starfish (echinoderms) are believed to have planktotrophic larvae (3-5). Planktotrophic larvae need to be fed to commence metamorphosis; thus, their development proceeds depending on the larval nutritional state (6). Some species change their strategies and develop through lecithotrophic larvae (3-5). In contrast to that of planktotrophic larvae, the development of lecithotrophic larvae proceeds in a cascade-like manner because they do not feed before metamorphosis $(4,5)$. However, whether these lecithotrophic larvae sense environmental cues to commence metamorphosis is not clear.

After lecithotrophy, some starfish species retain their sensory apparatus, brachiolar arms (4). Many planktotrophic starfish larvae use their brachiolar arms to sense environmental cues about where to settle (7). This suggests that these species have continued to sense environmental cues, even after their transition to lecithotrophy. Some lecithotrophic paxillosidan species, such as Astropecten latespinosus Meissner, 1892, however, do not possess brachiolar arms (8-10).

Here we investigated whether lecithotrophic larvae could sense environmental cues by testing whether larvae of $A$. latespinosus commenced metamorphosis in seawater containing sand from the habitat of adult specimens. During this experiment, we also investigated when larvae became competent for metamorphosis. Previously, Komatsu (8) stated that larvae began to develop juvenile rudiments at around 30 hours post-fertilization (hpf), after the gastrula elongated along the archenteron (Fig. A1b) (8). Juvenile rudiment development then proceeded until about 72-96 hpf (Fig. A1c, d) (8). Komatsu (8) reported that larvae metamorphosed to juveniles after 75 hpf (Fig. A1e, f), although she did not experimentally examine the time to acquisition of competency (8).

We collected adult specimens of A. latespinosus from Notojima Island, Ishikawa Prefecture, Japan; and we obtained fertilized eggs as described previously (8). We introduced the 


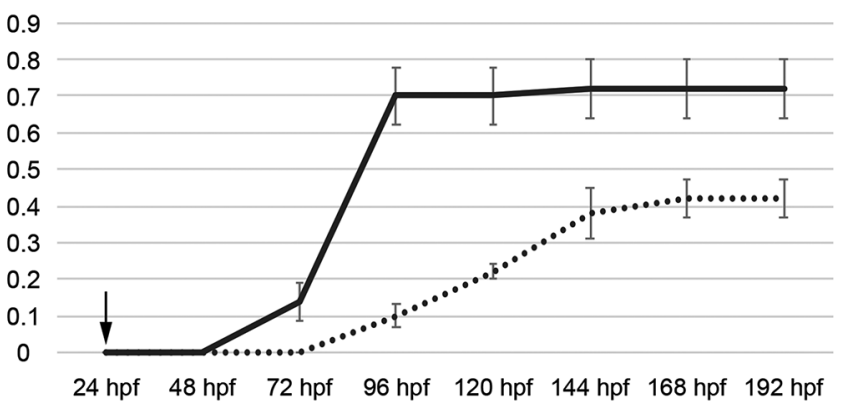

Figure 1. Effect of culture with natural sand from habitat on metamorphosis. Ten Astropecten latespinosus larvae were incubated with natural sand in $2 \mathrm{~mL}$ of artificial seawater (Marin-Tech, Aichi, Japan) in 12-well plates at $22{ }^{\circ} \mathrm{C}$. Metamorphosis ratios were recorded every 24 hours after treatment. The solid and dotted lines indicate the ratios under incubation of larvae with and without natural sand from their habitat, respectively. The arrow indicates the time of treatment commencement. hpf, hours post-fertilization.

habitat sand to the wells of the 24-hpf larvae, corresponding to gastrula ( $n=50$ from 3 batches; Fig. A1a). Then we cultured larvae and every day for one week counted the number of larvae that completed metamorphosis. We considered the ability to induce metamorphosis to have been achieved when the whole larval body had been absorbed and the juvenile rudiment had developed (Fig. A1). For statistical analysis, we used ANOVA to evaluate differences in the effects of the substrate on metamorphosis, as used in our previous work (11).

In the seawater without substrate, larvae did not metamorphose before 72 hpf (Fig. 1; Table A1). Small numbers of larvae (5 of 50 larvae) metamorphosed into juveniles after 96 hpf (Fig. 1; Table A1), although the metamorphosis ratio was less than $50 \%$ (21 of 50 larvae; Fig. 1; Table A1). However, when substrates were added to the seawater, small numbers of larvae (7 of 50 larvae) were induced to metamorphose even at 72 hpf (Fig. 1; Table A1). More than $70 \%$ of larvae (36 of 50 larvae) metamorphosed after 96 hpf (Fig. 1; Table A1). At 192 hpf, significant differences in the metamorphosis ratios were observed between treatments $(P=0.009$, ANOVA). These results indicated that A. latespinosus can sense environmental cues, such as natural sand, to commence metamorphosis. We also found that most of the larvae metamorphosed at 72-96 hpf (Fig. 1), suggesting that they became competent around $72 \mathrm{hpf}$.

In planktotrophic larvae of starfish, Murabe et al. (7) found that brachiolar arms perform a critical role in receiving environmental cues for metamorphosis (7). Recently, we suggested that retinoic acid (RA) signaling mediated the commencement of the metamorphosis process after settlement (11), through RA synthesis by retinal dehydrogenase (RALDH) and binding to retinoic acid receptor (RAR) and retinoid $\mathrm{X}$ receptor (RXR) (12). As shown, we found that paxillosidan larvae also received environmental cues to commence metamorphosis, though they use different apparatuses from brachiolar arms for reception; thus, it is unclear whether RA signaling involves metamorphosis regulation in this group.

Here we examined whether the commencement of metamorphosis was also mediated by RA signaling in A. latespinosus. First, we investigated the effect of exogenous RA treatment of competent larvae ( $n=40$ from 3 batches). Because more than half of 72-hpf larvae treated with habitat sand completed metamorphosis in 24 hours (Fig. 1), we tested the effect of exogenous RA on 72-hpf larvae. We found that exogenous RA $\left(1 \mu \mathrm{mol} \mathrm{L}{ }^{-1}\right)$ treatment induced metamorphosis (32 of 40 larvae; Fig. 2a, c; Table A2). The larvae commenced metamorphosis immediately after treatment and completed their transitions to juveniles in 24 hours. In contrast, only 1 out of 40 dimethyl sulfoxide (DMSO)-treated larvae metamorphosed (Fig. 2b, c; Table A2). We observed that the presence of RA significantly affected the metamorphosis ratio $(P<0.001$, ANOVA). These results suggest that RA mediates internal signaling to commence the metamorphosis of $A$. latespinosus.

Additionally, we investigated the effect of exogenous RA treatment of larvae of various ages on metamorphosis in order to test whether RA also affected the timing of larval competence to respond to cues for metamorphosis. We treated 24and 48-hpf larvae with RA $\left(1 \mu \mathrm{mol} \mathrm{L}{ }^{-1}\right)$ and counted the number of metamorphosed larvae every 24 hours until $96 \mathrm{hpf}$ ( $n=30$ and 40 from 3 batches, respectively). We observed that metamorphosis was induced only after $72 \mathrm{hpf}$ in both cases ( 3 of 30 and 2 of 40 with 24- and 48-hpf initiations, respectively; Fig. 2d, e; Tables A3, A4). Thus, regardless of when the larvae were treated with RA, they responded and metamorphosed at $72 \mathrm{hpf}$, which is comparable to the stage at which larvae acquire competence to metamorphose during normal development (Figs. 1, 2d, e). Furthermore, at 96 hpf, almost half of the larvae metamorphosed (15 of 30 and 19 of 40 from 3 batches with 24- and 48-hpf initiations, respectively; Fig. 2d, e; Tables A3, A4). We found significant differences at $96 \mathrm{hpf}$ in the batches with 24- and 48-hpf initiations ( $P=0.034$ and $P=0.019$, respectively, ANOVA). These timelines are similar to those induced by a substrate (Fig. 1). These results suggest that RA does not affect the development of competence for metamorphosis, but rather functions as an internal mediator of the signaling to commence metamorphosis when added to competent larvae.

Next, we investigated whether endogenous RA synthesis is required for metamorphosis. To investigate the effect of treatment with DEAB (N,N-diethylaminobenzaldehyde), an RA synthesis inhibitor, on metamorphosis, we treated 72-hpf larvae with DEAB $\left(300 \mu \mathrm{mol} \mathrm{L}^{-1}\right)$ and natural sand in the experiments described above; and we counted the larvae that had completed metamorphosis 24 hours after treatment ( $n=40$ from 3 batches). As a control, we treated 72-hpf larvae with DMSO and natural sand. More than half of the DMSO-treated larvae transitioned to juveniles (26 of 40 larvae; Fig. 3b, c; Table A5). In contrast, 

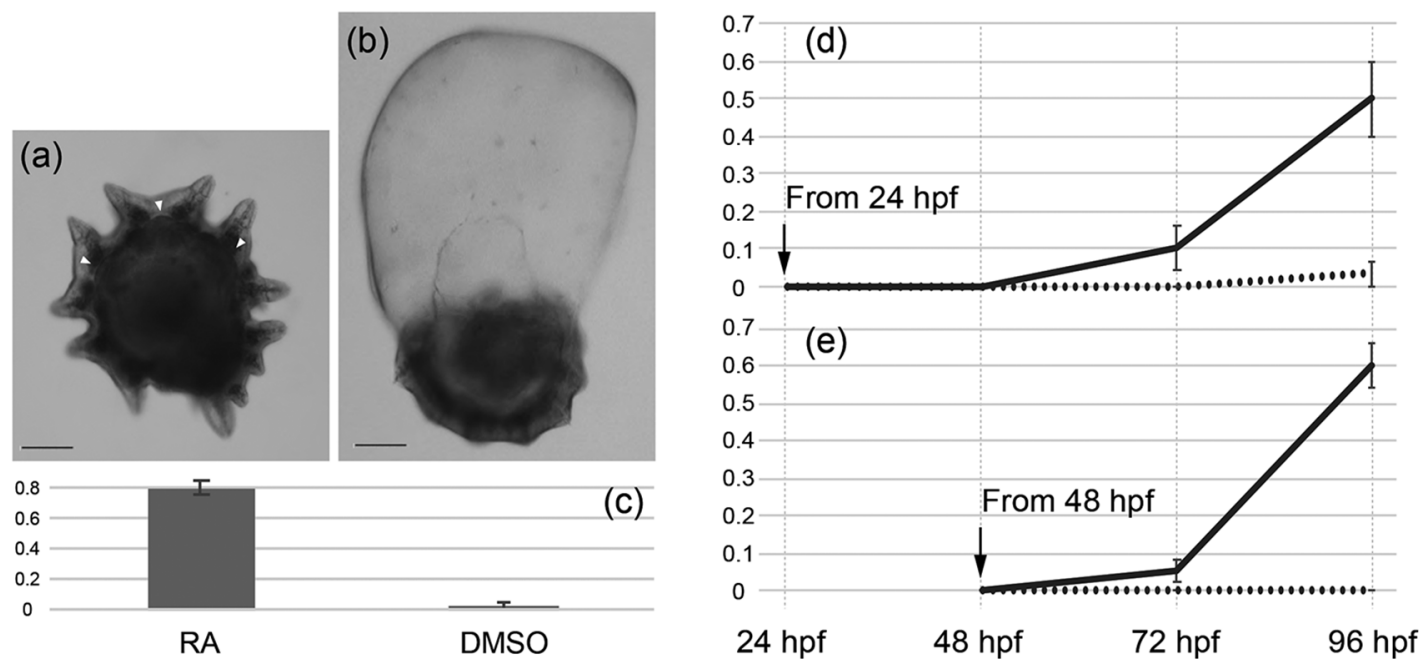

Figure 2. Metamorphosis induction by exogenous retinoic acid (RA) treatment in Astropecten latespinosus. Reagent treatment experiments were conducted as in our previous work (11). (a) Metamorphosis induced by RA. (b) Control larvae treated with dimethyl sulfoxide (DMSO). (c) Metamorphosis induction ratios under the RA and DMSO treatments obtained 24 hours after treatment. The scale bars indicate $100 \mu \mathrm{m}$, and the arrows indicate the primary podia. (d, e) Metamorphosis induction ratios under the RA (solid lines) and DMSO (dotted lines) treatments obtained every 24 hours after the commencement of treatment of 24- and 48-hours post-fertilization (hpf) larvae, respectively.

DEAB treatment decreased the number of metamorphosed larvae (6 of 40 larvae; Fig. 3a, c; Table A5). The metamorphosis ratio was significantly suppressed by DEAB treatment $(P=0.022$, ANOVA). We observed particular larval behavior in the DEAB treatment prior to metamorphosis, such as attachment to the substrate with rudiments. Thus, larvae were likely to sense the environmental cue but did not commence metamorphosis. These findings suggest that endogenous RA synthesis is required for the commencement of metamorphosis.

RA binding to RAR is required for RA signaling activation (12). Thus, we investigated the effect of RAR antagonist treatment on metamorphosis to test the hypothesis that RA signaling pathways mediate the metamorphosis process. We treated 72-hpf larvae ( $n=40$ from 3 batches) with RO415253 (RO, Focus Biomolecules, Plymouth Meeting, PA; $1 \mu \mathrm{mol} \mathrm{L} \mathrm{L}^{-1}$ ), RAR antagonist, and the natural sand used above; and we counted the number of metamorphosed larvae after 24 hours. As a control, we treated 72-hpf larvae with DMSO and natural sand. Under the DMSO treatment, $67.5 \%$ of larvae (27 of 40 larvae) transitioned to juveniles (Fig. 3e, f; Table A6). In contrast, no larva metamorphosed under the RO treatment (Fig. 3d, f; Table A6). The metamorphosis ratio was significantly repressed by RO treatment $(P=0.008$, ANOVA). As we observed with DEAB treatment, larvae also stopped floating and attached to the substrate with rudiments after RO treatment.

As shown previously, exogenous RA treatment induces metamorphosis in 72-hpf larvae (Fig. 2). To support the idea that RA binding to RAR is required for metamorphosis, we examined whether RO treatment blocked metamorphosis induced by RA treatment. We treated 72-hpf larvae $(n=40$ from 3 batches) with RA $\left(1 \mu \mathrm{mol} \mathrm{L}{ }^{-1}\right)$ or RA $\left(1 \mu \mathrm{mol} \mathrm{L}{ }^{-1}\right)$ plus RO $\left(1 \mu \mathrm{mol} \mathrm{L}^{-1}\right)$. In the RA-only treatment, $77.5 \%$ of larvae (31 of 40 larvae) metamorphosed (Fig. 3g-i; Table A7). Conversely, the RA $\left(1 \mu \mathrm{mol} \mathrm{L}^{-1}\right)$ plus RO $\left(1 \mu \mathrm{mol} \mathrm{L}^{-1}\right)$ treatment induced metamorphosis in only $12.5 \%$ of larvae (5 of 40 larvae; Fig. 3h, k; Table A7). RO significantly repressed the metamorphosis ratio $(P<0.001$, ANOVA). These data suggest that RA signaling activation through RA binding to RAR is required for the commencement of metamorphosis.

We examined the expression patterns of genes involved in RA signaling. We confirmed their orthologies by constructing phylogenic trees (Figs. A2-A5). In conclusion, from our de novo transcriptome, we identified three raldh genes (raldha, raldhb, and raldhc), a single rar, and a single rxr. We also investigated the spatial expression patterns of the three raldh genes, $r a r$, and $r x r$ by whole-mount in situ hybridization of 72-hpf larvae (Fig. 4). We identified the expression of two types of receptor, rar and $r x r$, in the juvenile rudiment (Fig. $4 \mathrm{j}-1$ and $\mathrm{m}-\mathrm{O}$, respectively), as well as that of raldha, raldhb, and raldhc (Fig. 4a-c, d-f, and g-i, respectively). Especially in the juvenile rudiment, all genes were expressed in the epidermis region in a different expression pattern: patchwise expression of raldh genes and broad expression of rar and rxr (Fig. 4c, f, i, 1, o). We also found that all genes except raldhc were expressed in hydrolobes (primordium of primary podia and tube feet; Fig. 4c, f, 1, o). These expression patterns were consistent with the idea that hydrolobes are used for 


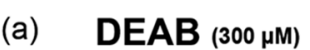

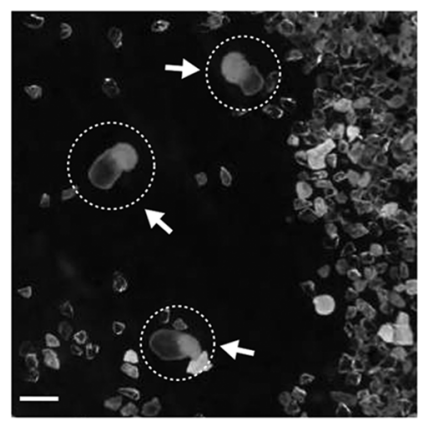

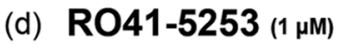

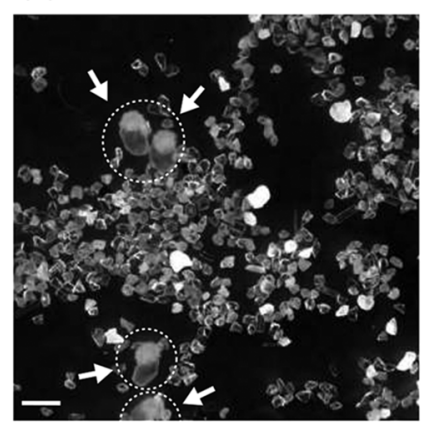

(b)

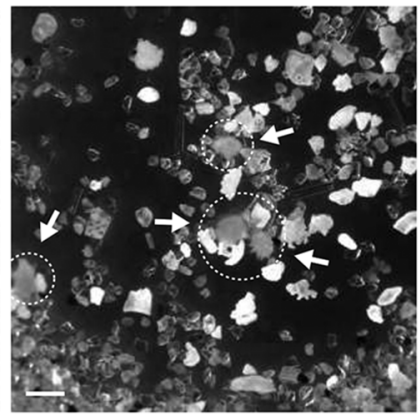

(e)

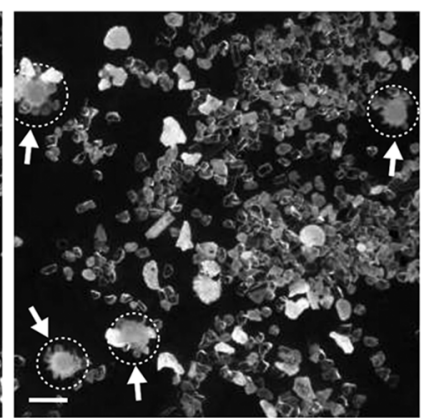

(c)

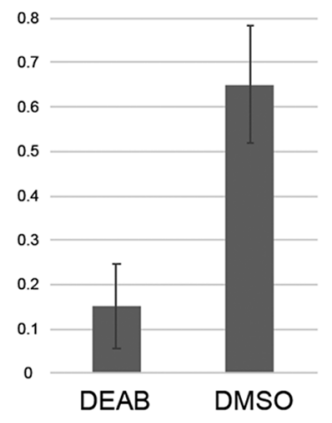

(f)

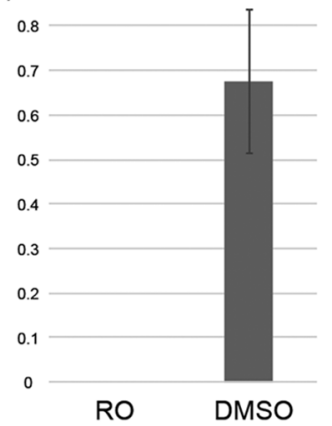

(g) RA

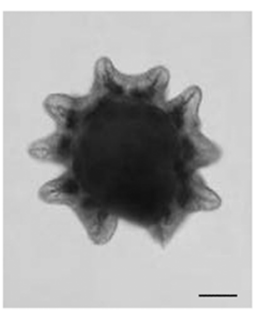

(h) RA+RO

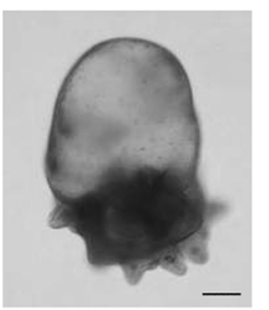

(i)

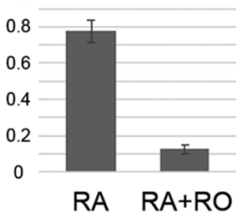

Figure 3. Effect of inhibition of retinoic acid (RA) synthesis or RA binding to retinoic acid receptor (RAR) on metamorphosis. (a) Astropecten latespinosus larvae in which metamorphosis was inhibited by N,Ndiethylaminobenzaldehyde (DEAB) $\left(300 \mu \mathrm{mol} \mathrm{L}^{-1}\right)$ treatment. Under the dimethyl sulfoxide (DMSO) treatment, larvae correctly completed metamorphosis (b). (c) Metamorphosis ratios under the DEAB $\left(300 \mu \mathrm{mol} \mathrm{L}{ }^{-1}\right)$ and DMSO treatments. (d, e) Metamorphosis-inhibited larvae and completed juveniles under the RO41-5253 (RO; $\left.1 \mu \mathrm{mol} \mathrm{L}^{-1}\right)$ and DMSO treatments, respectively. (f) Metamorphosis ratios under the $\mathrm{RO}\left(1 \mu \mathrm{mol} \mathrm{L}^{-1}\right)$ and DMSO treatments. Larvae treated with RA $\left(1 \mu \mathrm{mol} \mathrm{L}^{-1}\right)(\mathrm{g})$ and RA $\left(1 \mu \mathrm{mol} \mathrm{L}^{-1}\right)$ plus RO $\left(1 \mu \mathrm{mol} \mathrm{L}^{-1}\right)$ (h). (i) Metamorphosis ratios. The dotted circles and arrows indicate larvae and juveniles, respectively. The scale bars in (a-e) and $(\mathrm{g}, \mathrm{h})$ indicate 500 and $100 \mu \mathrm{m}$, respectively.

sensation of environmental cues in Paxillosida $(13,14)$. These data support the conclusion that RA signaling mediates the metamorphosis process in A. latespinosus.

Here we provided the evidence that metamorphosis is triggered by environmental cues in A. latespinosus larvae. When we introduced natural sand from the A. latespinosus habitat, the larvae stopped floating, became attached to the substrate, and commenced metamorphosis (Fig. 1). Furthermore, our data suggested that RA signaling mediated the commencement of metamorphosis upon environmental cue reception. Exogenous RA treatment of competent larvae induced metamorphosis (Fig. 2), and metamorphosis was suppressed by the inhibition of two distinct RA signaling pathways (Fig. 3): RA synthesis (Fig. 3a-c) and RA binding to RAR (Fig. 3di). The spatial expression pattern of RA signaling-related genes is consistent with the results described above (Fig. 4). Particularly, overlapping expression of two kinds of receptor (rar and $r x r$ ) was observed in juvenile rudiments of competent larvae (Fig. $4 \mathrm{j}-1$ and $\mathrm{m}-\mathrm{O}$, respectively). It should be noted that we did not examine the gene function analysis in this study. To strengthen our hypothesis, future study should focus on the function of each regulatory component.

Planktonic starfish larvae sense environmental cues for metamorphosis with brachiolar arms (7); but paxillosidan larvae, even those that are planktonic, lack brachiolar arms $(4,14)$. This absence is regarded as a secondary loss due to the transition to a sandy habitat (15). In this study, we found that metamorphosis of A. latespinosus is induced by culture with natural sand from its habitat, suggesting that paxillosidan larvae also respond to environmental cues for metamorphosis. Despite our findings, how paxillosidan larvae sense environmental cues remains unclear.

Previously, several researchers suggested that tube feet (primary podia) are used as the sensory apparatus for the reception of environmental cues in this group $(13,14)$. Yet Komatsu (8) and Oguro et al. (16) stated that tube feet did not appear before metamorphosis was mostly completed in A. latespinosus and Astropecten scoparius $(8,16)$. Whether larvae sense environmental cues with this structure is difficult to judge based on hydrolobe morphology. We suggest that researchers' attention 


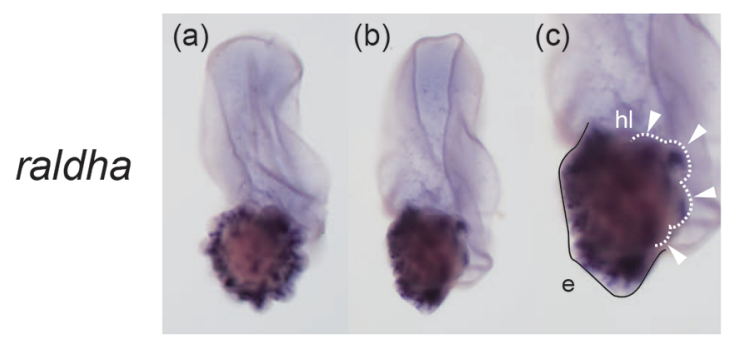

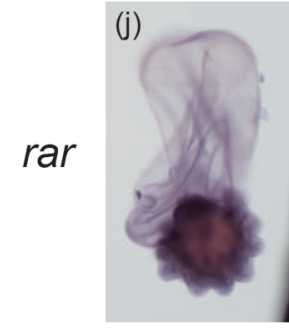

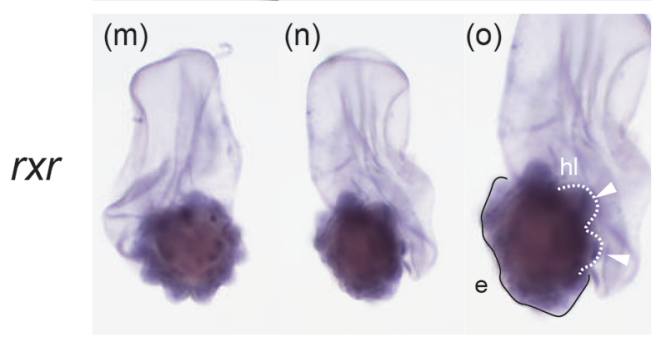

(k)

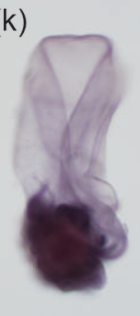

(l)

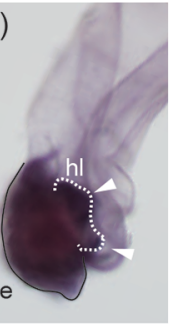

(o) (g)
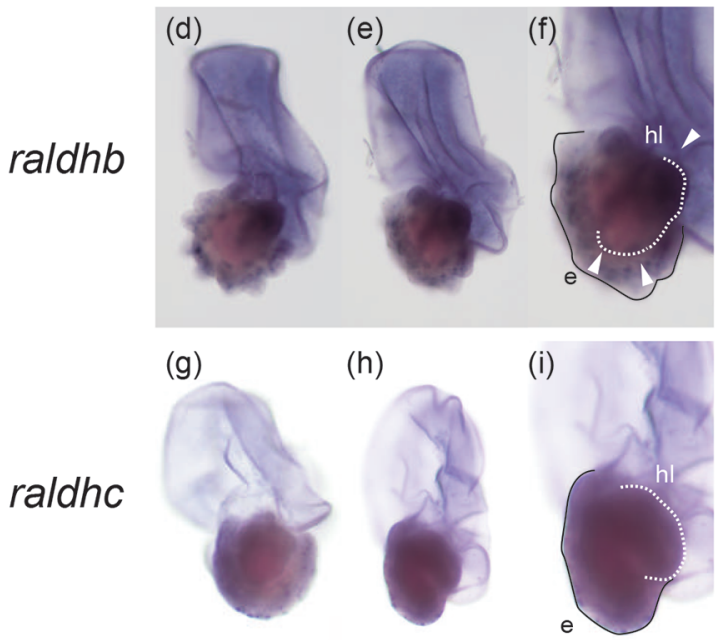

(e)
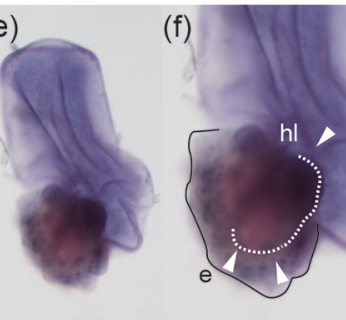

(i) (h)

Figure 4. Spatial expression pattern of retinoic acid (RA) signaling components. $(a-c),(d-f),(g-i),(j-1)$, and (m-o) show the expression patterns of raldha, raldhb, raldhc, rar, and rxr, respectively, in 72-hours postfertilization (hpf) larvae. In (c), (f), (i), (1), and (o), white dotted lines and black solid lines indicate hydrolobes (hl) and epidermis of juvenile rudiment (e), respectively. Arrowheads point toward the expression in hydrolobes. In situ hybridization was performed as in our previous work (17).

be broadened to juvenile structures in efforts to identify the sensory apparatus for environmental cue detection in paxillosidan species.

\section{Acknowledgments}

Our work was supported by Japan Society for the Promotion of Science KAKENHI (Grant-in-Aid for Scientific Research) grants 15KT0074 and 18H04004. We thank the Ibaraki Prefectural Oarai Aquarium for providing the seawater for culturing of adult starfish.

\section{Data Accessibility}

We deposited the gene sequences (raldha, raldhb, raldhc, rar, and $r x r$ ) in the DNA Data Bank of Japan (DDBJ; LC485972, LC485973, LC485974, LC485975, LC485976). We also supply the dataset for phylogenetic analysis in supplementary datasets 1 and 2 (available online). The raw reads of transcriptomes are available from the DDBJ Sequence Reads Archives (DRA008444).

\section{Literature Cited}

1. Jägersten, G. 1972. Evolution of the Metazoan Life Cycle. Academic Press, London.

2. Morse, D. E. 1990. Recent progress in larval settlement and metamorphosis: closing the gaps between molecular biology and ecology. Bull. Mar. Sci. 46: 465-483.

3. Oguro, C. 1989. Evolution of the development and larval types in asteroids. Zool. Sci. 6: 199-210.

4. McEdward, L. R., and B. G. Miner. 2001. Larval and life-cycle patterns in echinoderms. Can. J. Zool. 79: 1125-1170.

5. Byrne, M. 2006. Life history diversity and evolution in the Asterinidae. Integr. Comp. Biol. 46: 243-254.

6. McEdward, L. R. 1997. Reproductive strategies of marine benthic invertebrates revisited: facultative feeding by planktotrophic larvae. Am. Nat. 150: 48-72.

7. Murabe, N., H. Hatoyama, M. Komatsu, H. Kaneko, and Y. Nakajima. 2007. Adhesive papillae on the brachiolar arms of brachiolaria larvae in two starfishes, Asterina pectinifera and Asterias amurensis, are sensors for metamorphic inducing factor(s). Dev. Growth Differ. 49: 647-656.

8. Komatsu, M. 1975. On the development of the sea-star, Astropecten latespinosus Meissner. Biol. Bull. 148: 49-59.

9. Komatsu, M. 1982. Development of the sea-star Ctenopleura fisheri. Mar. Biol. 66: 199-205.

10. Komatsu, M., and S. Nojima. 1985. Development of the seastar, Astropecten gisselbrechti Doderlein. Pac. Sci. 39: 274-282. 
11. Yamakawa, S., Y. Morino, M. Honda, and H. Wada. 2018. The role of retinoic acid signaling in starfish metamorphosis. EvoDevo 9: 10.

12. Rhinn, M., and P. Dolle. 2012. Retinoic acid signalling during development. Development 139: 843-858.

13. Byrne, M. 2013. Asteroid evolutionary developmental biology and ecology. Pp. 51-58 in Starfish Biology and Ecology of the Asteroidea, J. M. Lawrence, ed. John Hopkins University Press, Baltimore.

14. Pernet, B., B. T. Livingston, C. Sojka, and D. Lizárraga. 2017. Embryogenesis and larval development of the seastar Astropecten armatus. Invertebr. Biol. 136: 121-133.

15. Linchangco, G. V., D. W. Foltz, R. Reid, J. Williams, C. Nodzak, A. M. Kerr, A. K. Miller, R. Hunter, N. G. Wilson, W. J. Nielsen et al. 2017. The phylogeny of extant starfish (Asteroidea: Echinoder- mata) including Xyloplax, based on comparative transcriptomics. Mol. Phylogenet. Evol. 115: 161-170.

16. Oguro, C., M. Komatsu, and Y. T. Kano. 1976. Development and metamorphosis of the sea-star, Astropecten scoparius Valenciennes. Biol. Bull. 151: 560-573.

17. Morino, Y., H. Koga, K. Tachibana, E. Shoguchi, M. Kiyomoto, and H. Wada. 2012. Heterochronic activation of VEGF signaling and the evolution of the skeleton in echinoderm pluteus larvae. Evol. Dev. 14: 428-436.

18. Tanabe, A. S. 2011. Kakusan 4 and Aminosan: two programs for comparing nonpartitioned, proportional and separate models for combined molecular phylogenetic analyses of multilocus sequence data. Mol. Ecol. Resour. 11: 914-921.

19. Ronquist, F., and J. P. Huelsenbeck. 2003. MrBayes 3: Bayesian phylogenetic inference under mixed models. Bioinformatics 19: 1572-1574.

\section{Appendix}

$24 \mathrm{hpf}$

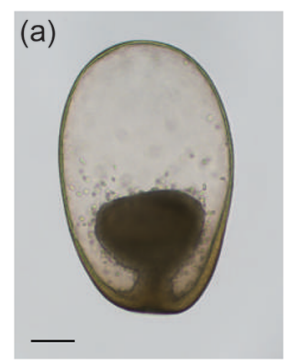

$96 \mathrm{hpf}$

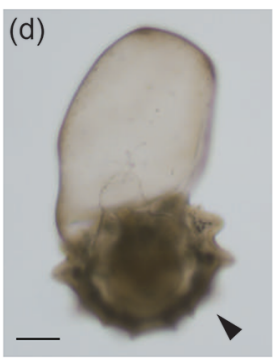

$48 \mathrm{hpf}$

(b)

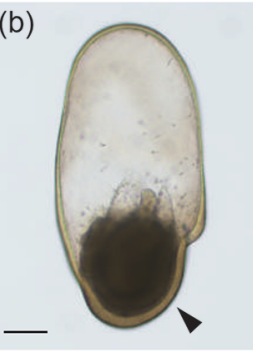

Metamorphosis

(e)

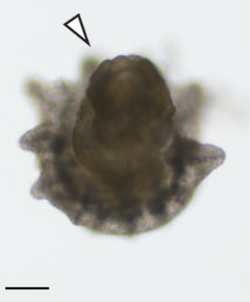

$72 \mathrm{hpf}$

(c)

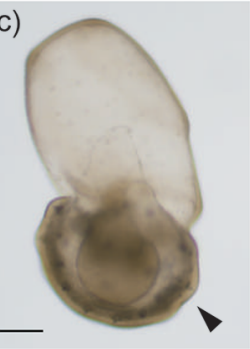

Juvenile

(f)

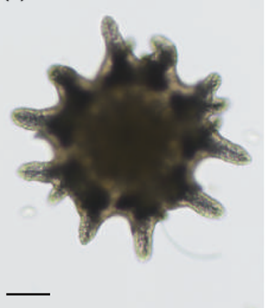

Figure A1. Developmental process of Astropecten latespinosus. (a-d) Larvae at 24, 48, 72, and 96 hours postfertilization (hpf), respectively. After the larvae commence metamorphosis, the juvenile rudiments develop; the larval bodies are absorbed, as in (e); and the larvae finally transition to juveniles (f). The black arrowheads indicate the juvenile rudiment, and the white arrowhead indicates the absorbed larval body. Scale bars: $100 \mu \mathrm{m}$. 


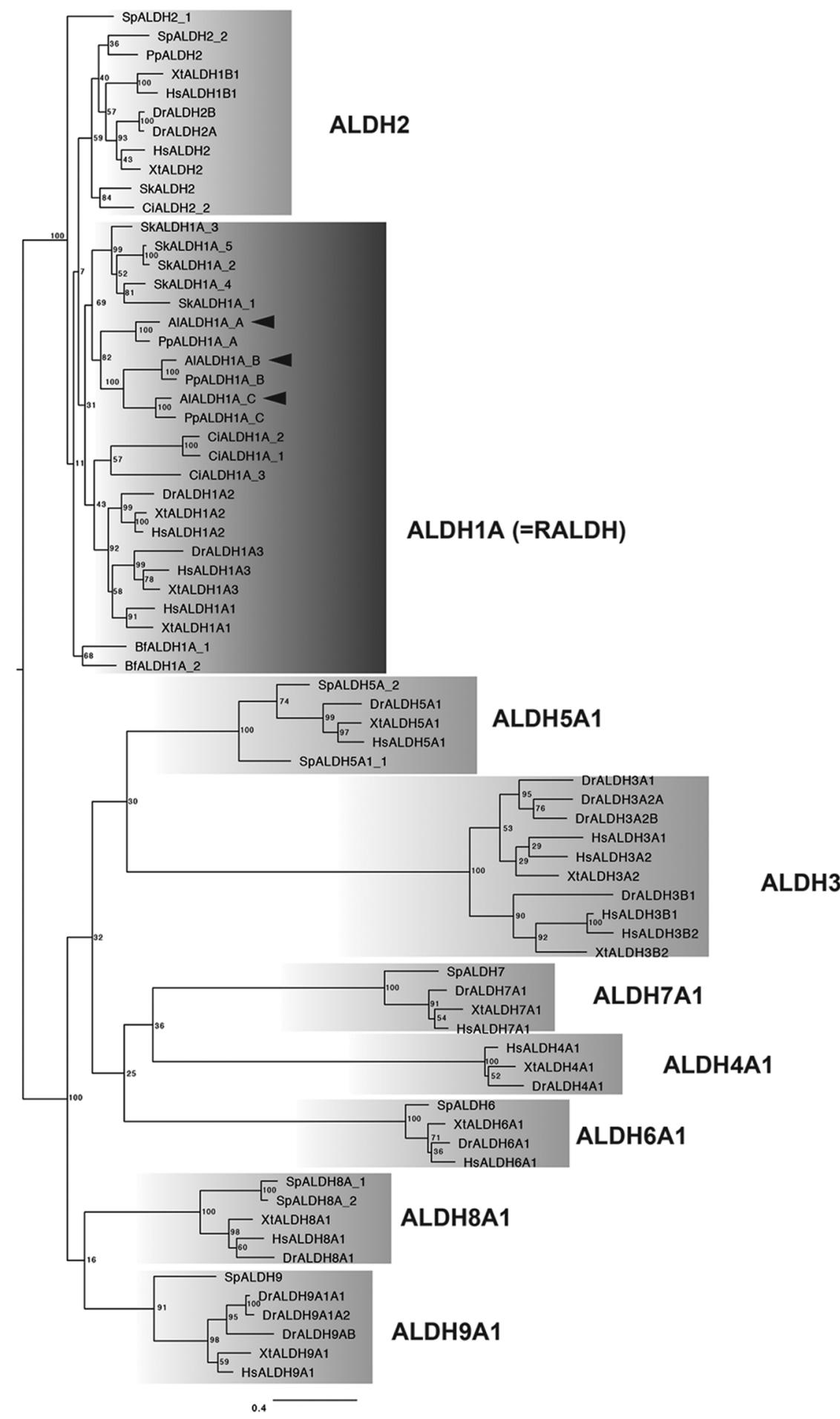

Figure A2. Maximum likelihood tree of the aldehyde dehydrogenase (ALDH) family. We constructed the tree of the aldehyde dehydrogenase (aldh) gene family to identify raldh (aldhla) genes in Astropecten latespinosus. In these trees, the phylogeny was not clearly dissolved in the clade including raldh, aldh1b, and aldh2, although we found that raldh genes of starfish (A. latespinosus and Patiria pectinifera) made a clade with raldh genes of a hemicordate previously identified with comparatively high support value. The phylogenic tree was constructed as in our previous work (11). Al (starfish), Astropecten latespinosus; $\mathrm{Bf}$ (amphioxus), Branchiostoma floridae; $\mathrm{Ci}$ (tunicate), Ciona intestinalis; Dr (zebrafish), Danio rerio; Hs (human), Homo sapiens; Pp (starfish), Patiria pectinifera; Sk (acorn worm), Saccoglossus kowalevskii; Sp (sea urchin), Strongylocentrotus purpuratus; Xt (frog), Xenopus tropicalis. 


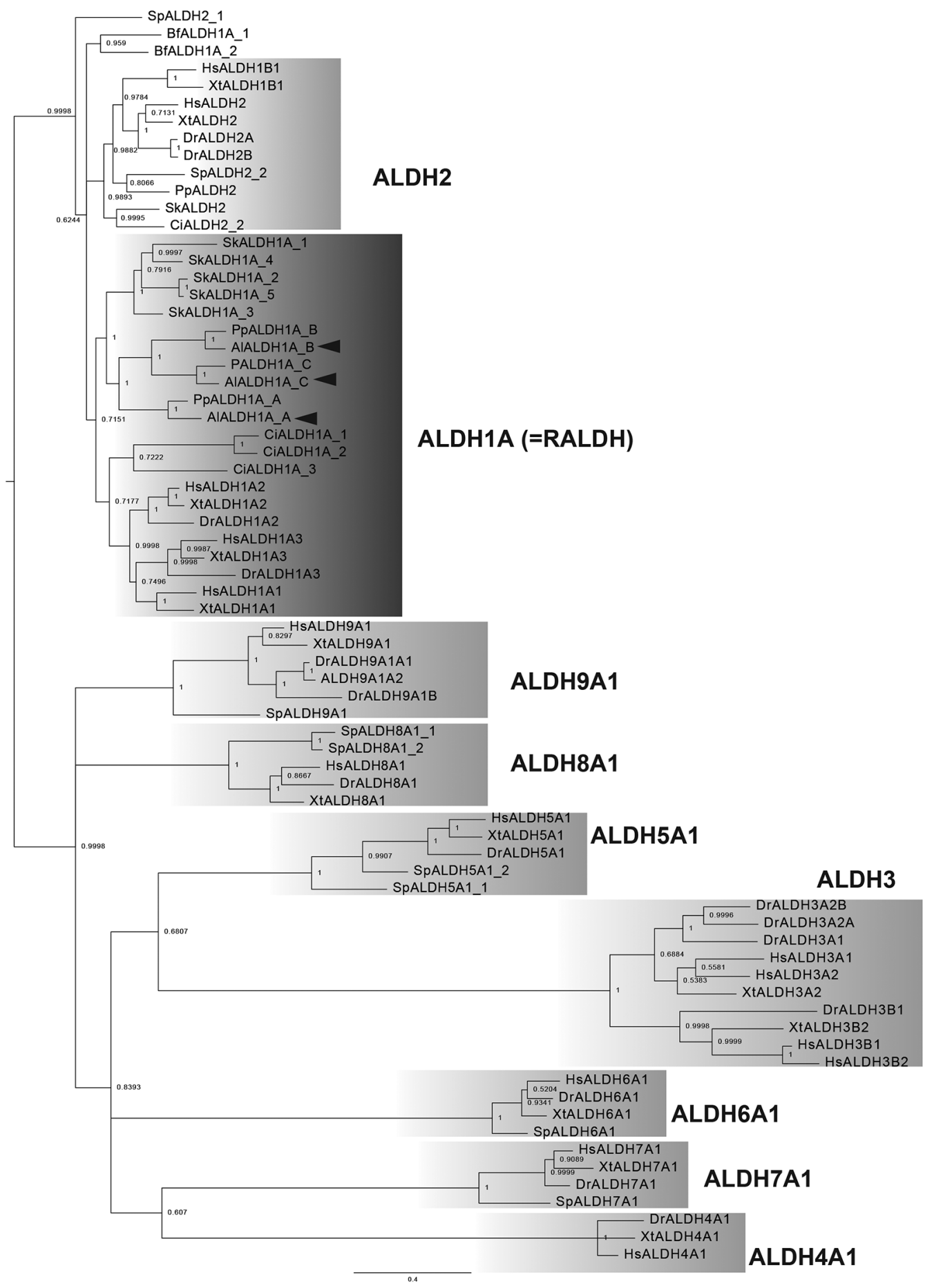

Figure A3. Bayesian phylogenic tree of the aldehyde dehydrogenase (ALDH) family. Aminosan (ver. 1.0.2016.11.07) was used to choose the best-fitting amino acid substitution model, showing the $\mathrm{LG}+\mathrm{G}$ model as the top selected (18). We calculated Bayesian phylogenic inferences with MrBayes (ver. 3.2.7a) (19), using the LG model and a gamma distribution for rate variation. Four chains were run for 5 million generations, and trees were sampled every 100 generations with a 25\% burn-in. Al (starfish), Astropecten latespinosus; Bf (amphioxus), Branchiostoma floridae; Ci (tunicate), Ciona intestinalis; Dr (zebrafish), Danio rerio; Hs (human), Homo sapiens; Pp (starfish), Patiria pectinifera; Sk (acorn worm), Saccoglossus kowalevskii; Sp (sea urchin), Strongylocentrotus purpuratus; Xt (frog), Xenopus tropicalis. 


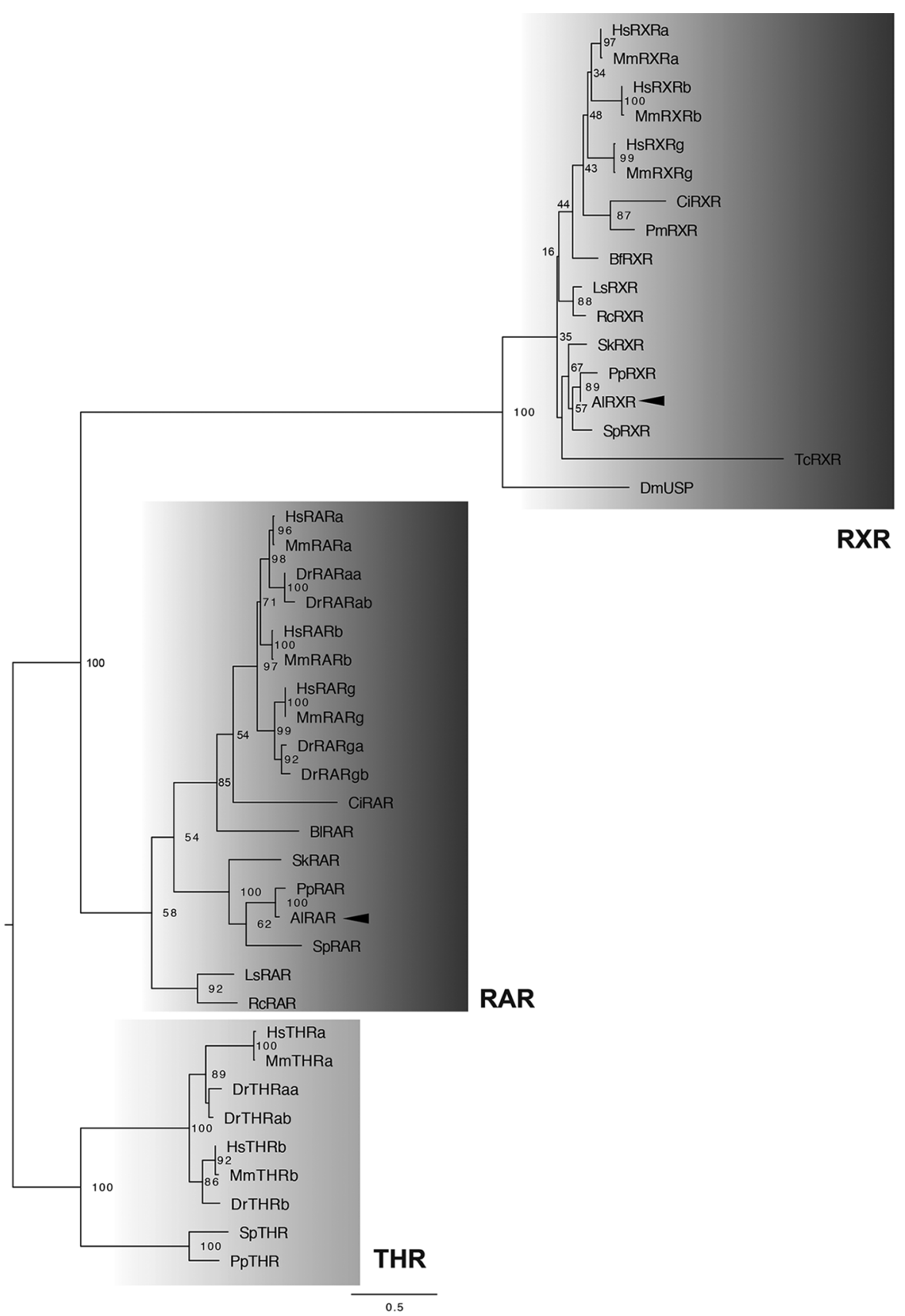

Figure A4. Maximum likelihood tree of retinoic acid receptor (RAR), retinoid X receptor (RXR), and thyroid hormone receptor (THR). In phylogenic trees of $r a r, r x r$, and outgroup thr, we found that rar and rxr of Astropecten latespinosus were respectively positioned in the clade of rar and rxr. $\mathrm{Al}$ (starfish), Astropecten latespinosus; $\mathrm{Bf}$ (amphioxus), Branchiostoma floridae; $\mathrm{Bl}$ (amphioxus), Branchiostoma lanceolatum; Ci (tunicate), Ciona intestinalis; Dm (fly), Drosophila melanogaster; Dr (zebrafish), Danio rerio; Hs (human), Homo sapiens; Ls (snail), Lymnaea stagnalis; Mm (mouse), Mus musculus; Pm (tunicate), Polyandrocarpa misakiensis; Pp (starfish), Patiria pectinifera; Rc (snail), Reishia clavigera; Sk (acorn worm), Saccoglossus kowalevskii; Sp (sea urchin), Strongylocentrotus purpuratus; Tc ( jellyfish), Tripedalia cystophora. 


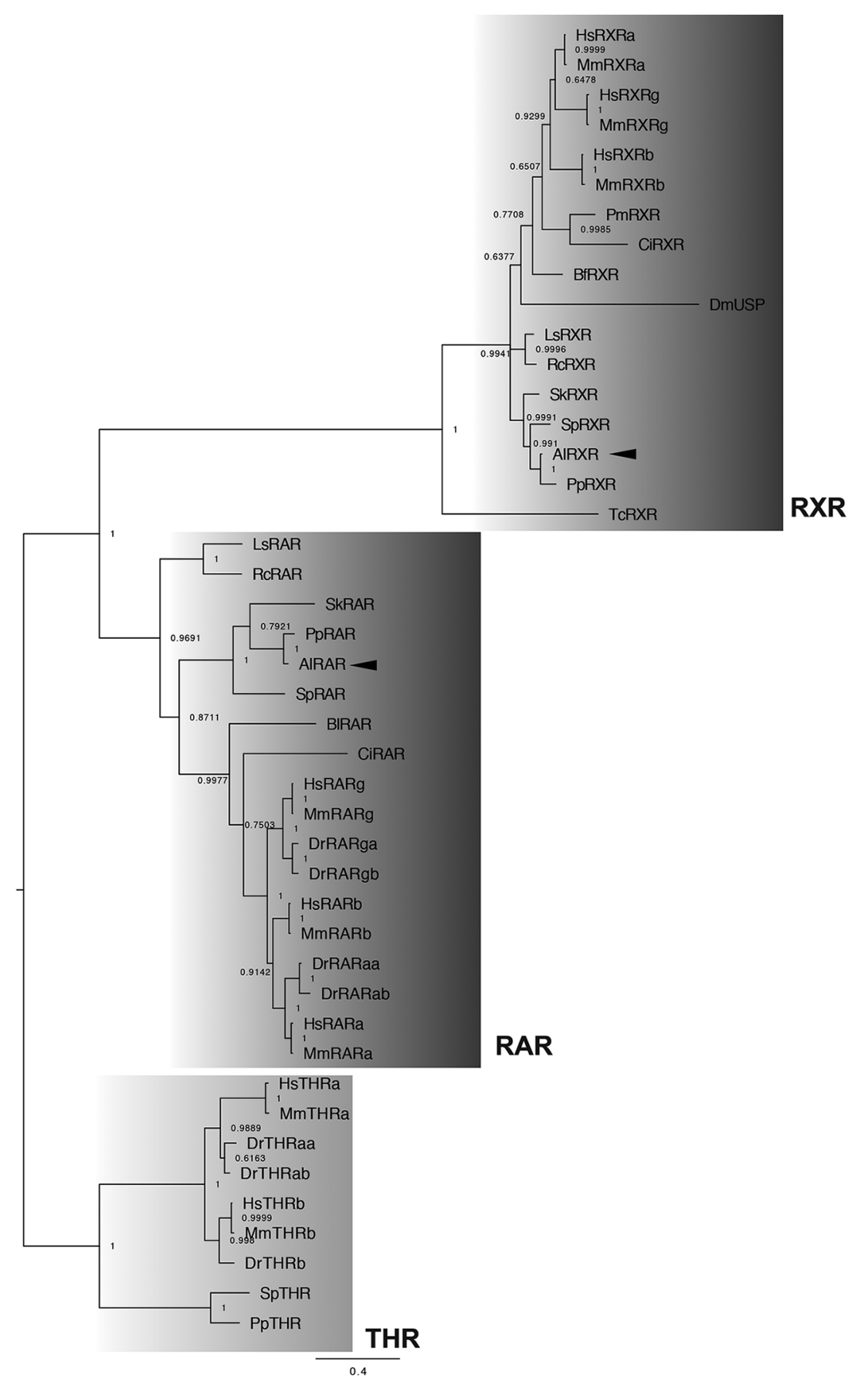

Figure A5. Bayesian phylogenic tree of retinoic acid receptor (RAR), retinoid X receptor (RXR), and THR. We used the LG $+\mathrm{G}$ model as the best-fitting amino acid substitution model. Al (starfish), Astropecten latespinosus; $\mathrm{Bf}$ (amphioxus), Branchiostoma floridae; $\mathrm{Bl}$ (amphioxus), Branchiostoma lanceolatum; Ci (tunicate), Ciona intestinalis; Dm (fly), Drosophila melanogaster; Dr (zebrafish), Danio rerio; Hs (human), Homo sapiens; Ls (snail), Lymnaea stagnalis; Mm (mouse), Mus musculus; Pm (tunicate), Polyandrocarpa misakiensis; Pp (starfish), Patiria pectinifera; Rc (snail), Reishia clavigera; Sk (acorn worm), Saccoglossus kowalevskii; Sp (sea urchin), Strongylocentrotus purpuratus; Tc (jellyfish), Tripedalia cystophora. 
Table A1

Number of metamorphosed/treated larvae of each batch under seawater with and without substrate

\begin{tabular}{|c|c|c|c|c|c|c|c|c|c|c|}
\hline \multirow[b]{4}{*}{ Age (hpf) } & \multicolumn{10}{|c|}{ Number of metamorphosed/treated larvae } \\
\hline & \multicolumn{5}{|c|}{ Substrate $(+)$} & \multicolumn{5}{|c|}{ Substrate (-) } \\
\hline & \multicolumn{2}{|c|}{ Batch 1} & \multicolumn{2}{|c|}{ Batch 2} & \multirow{2}{*}{$\frac{\text { Batch } 3}{\text { Well } 1}$} & \multicolumn{2}{|c|}{ Batch 1} & \multicolumn{2}{|c|}{ Batch 2} & \multirow{2}{*}{$\frac{\text { Batch } 3}{\text { Well 1 }}$} \\
\hline & Well 1 & Well 2 & Well 1 & Well 2 & & Well 1 & Well 2 & Well 1 & Well 2 & \\
\hline 48 & $0 / 10$ & $0 / 10$ & $0 / 10$ & $0 / 10$ & $0 / 10$ & $0 / 10$ & $0 / 10$ & $0 / 10$ & $0 / 10$ & $0 / 10$ \\
\hline 72 & $2 / 10$ & $3 / 10$ & $0 / 10$ & $1 / 10$ & $1 / 10$ & $0 / 10$ & $0 / 10$ & $0 / 10$ & $0 / 10$ & $0 / 10$ \\
\hline 96 & $8 / 10$ & $8 / 10$ & $7 / 10$ & $8 / 10$ & $4 / 10$ & $0 / 10$ & $1 / 10$ & $2 / 10$ & $1 / 10$ & $1 / 10$ \\
\hline 120 & $8 / 10$ & $8 / 10$ & $7 / 10$ & $8 / 10$ & $4 / 10$ & $2 / 10$ & $2 / 10$ & $2 / 10$ & $3 / 10$ & $2 / 10$ \\
\hline 144 & $8 / 10$ & $8 / 10$ & $8 / 10$ & $8 / 10$ & $4 / 10$ & $3 / 10$ & $2 / 10$ & $6 / 10$ & $4 / 10$ & $4 / 10$ \\
\hline 168 & $8 / 10$ & $8 / 10$ & $8 / 10$ & $8 / 10$ & $4 / 10$ & $3 / 10$ & $4 / 10$ & $6 / 10$ & $4 / 10$ & $4 / 10$ \\
\hline 192 & $8 / 10$ & $8 / 10$ & $8 / 10$ & $8 / 10$ & $4 / 10$ & $3 / 10$ & $4 / 10$ & $6 / 10$ & $4 / 10$ & $4 / 10$ \\
\hline
\end{tabular}

hpf, hours post-fertilization.

Table A2

Number of metamorphosed larvae/treated larvae of each batch in retinoic acid (RA) or dimethyl sulfoxide (DMSO) treatment

\begin{tabular}{|c|c|c|c|c|}
\hline \multirow[b]{3}{*}{ Treatment } & \multicolumn{4}{|c|}{ Number of metamorphosed/treated larvae } \\
\hline & \multicolumn{2}{|c|}{ Batch 1} & \multirow{2}{*}{$\frac{\text { Batch } 2}{\text { Well } 1}$} & \multirow{2}{*}{$\frac{\text { Batch } 3}{\text { Well } 1}$} \\
\hline & Well 1 & Well 2 & & \\
\hline RA & $8 / 10$ & $8 / 10$ & $7 / 10$ & $9 / 10$ \\
\hline DMSO & $1 / 10$ & $0 / 10$ & $0 / 10$ & $0 / 10$ \\
\hline
\end{tabular}

Table A3

Number of metamorphosed larvae/treated larvae of each batch in retinoic acid (RA) or dimethyl sulfoxide (DMSO) treatment in the case that treatment was commenced at 24 hours postfertilization ( $h p f)$

\begin{tabular}{|c|c|c|c|c|c|c|}
\hline \multirow[b]{4}{*}{ Age (hpf) } & \multicolumn{6}{|c|}{ Number of metamorphosed/treated larvae } \\
\hline & \multicolumn{3}{|c|}{ RA } & \multicolumn{3}{|c|}{ DMSO } \\
\hline & Batch 1 & Batch 2 & Batch 3 & Batch 1 & Batch 2 & Batch 3 \\
\hline & Well 1 & Well 1 & Well 1 & Well 1 & Well 1 & Well 1 \\
\hline 48 & $0 / 10$ & $0 / 10$ & $0 / 10$ & $0 / 10$ & $0 / 10$ & $0 / 10$ \\
\hline 72 & $0 / 10$ & $1 / 10$ & $2 / 10$ & $0 / 10$ & $0 / 10$ & $0 / 10$ \\
\hline 96 & $3 / 10$ & $6 / 10$ & $6 / 10$ & $0 / 10$ & $0 / 10$ & $1 / 10$ \\
\hline
\end{tabular}


Table A4

Number of metamorphosed larvae/treated larvae of each batch in retinoic acid (RA) or dimethyl sulfoxide (DMSO) treatment in the case that treatment was commenced at 48 hours post-fertilization (hpf)

\begin{tabular}{|c|c|c|c|c|c|c|c|c|}
\hline \multirow[b]{4}{*}{ Age (hpf) } & \multicolumn{8}{|c|}{ Number of metamorphosed/treated larvae } \\
\hline & \multicolumn{4}{|c|}{ RA } & \multicolumn{4}{|c|}{ DMSO } \\
\hline & \multicolumn{2}{|c|}{ Batch 1} & \multirow{2}{*}{$\frac{\text { Batch } 2}{\text { Well } 1}$} & \multirow{2}{*}{$\frac{\text { Batch } 3}{\text { Well } 1}$} & \multicolumn{2}{|c|}{ Batch 1} & \multirow{2}{*}{$\frac{\text { Batch } 2}{\text { Well } 1}$} & \multirow{2}{*}{$\frac{\text { Batch } 3}{\text { Well } 1}$} \\
\hline & Well 1 & Well 2 & & & Well 1 & Well 2 & & \\
\hline 72 & $1 / 10$ & $0 / 10$ & $0 / 10$ & $1 / 10$ & $0 / 10$ & $0 / 10$ & $0 / 10$ & $0 / 10$ \\
\hline 96 & $7 / 10$ & $2 / 10$ & $5 / 10$ & $5 / 10$ & $0 / 10$ & $0 / 10$ & $0 / 10$ & $0 / 10$ \\
\hline
\end{tabular}

Table A5

Number of metamorphosed larvae/treated larvae of each batch in DEAB or dimethyl sulfoxide (DMSO) treatment

\begin{tabular}{lcccc}
\hline \hline & \multicolumn{3}{c}{ Number of metamorphosed/treated larvae } \\
\cline { 2 - 3 } & \multicolumn{2}{c}{ Batch 1 } & Batch 2 & Batch 3 \\
\cline { 2 - 3 } Treatment & Well 1 & Well 2 & Well 1 & Well 1 \\
\hline DEAB & $0 / 10$ & $4 / 10$ & $2 / 10$ & $0 / 10$ \\
DMSO & $6 / 10$ & $9 / 10$ & $8 / 10$ & $3 / 10$ \\
\hline
\end{tabular}

Table A6

Number of metamorphosed larvae/treated larvae of each batch in RO41-5253 (RO) or dimethyl sulfoxide (DMSO) treatment

\begin{tabular}{lcccc}
\hline \hline & \multicolumn{3}{c}{ Number of metamorphosed/treated larvae } \\
\cline { 2 - 3 } & \multicolumn{2}{c}{ Batch 1 } & Batch 2 & Batch 3 \\
\cline { 2 - 4 } Treatment & Well 1 & Well 2 & Well 1 & Well 1 \\
\hline RO & $0 / 10$ & $0 / 10$ & $0 / 10$ & $0 / 10$ \\
DMSO & $8 / 10$ & $8 / 10$ & $9 / 10$ & $2 / 10$ \\
\hline
\end{tabular}

Table A7

Number of metamorphosed larvae/treated larvae of each batch in retinoic acid $(R A)$ or retinoic acid plus RO41-5253 (RA+RO) treatment

\begin{tabular}{|c|c|c|c|c|}
\hline \multirow[b]{3}{*}{ Treatment } & \multicolumn{4}{|c|}{ Number of metamorphosed/treated larvae } \\
\hline & \multicolumn{2}{|c|}{ Batch 1} & \multirow{2}{*}{$\begin{array}{l}\text { Batch } 2 \\
\text { Well } 1\end{array}$} & \multirow{2}{*}{$\begin{array}{l}\text { Batch } 3 \\
\text { Well } 1\end{array}$} \\
\hline & Well 1 & Well 2 & & \\
\hline RA & $8 / 10$ & $8 / 10$ & $9 / 10$ & $6 / 10$ \\
\hline $\mathrm{RA}+\mathrm{RO}$ & $1 / 10$ & $2 / 10$ & $1 / 10$ & $1 / 10$ \\
\hline
\end{tabular}


Table A8

Sequences of primer for amplification of raldha, raldhb, raldhc, rar, and $\mathrm{rxr}$

\begin{tabular}{lll}
\hline \hline & \multicolumn{1}{c}{ Forward primer $\left(5^{\prime} \rightarrow 3^{\prime}\right)$} & Reverse primer including T3 promoter region $\left(5^{\prime} \rightarrow 3^{\prime}\right)$ \\
\hline raldha & gcaaccgatcgtcttcagaaggcacacatt & ATTAACCCTCACTAAAGGGAgcagaaaccacgtcttgtat \\
raldhb & accatcaatccggcaactggggagaagata & ATTAACCCTCACTAAAGGGAatattcataaaacgcacaca \\
raldhc & gacggtgatttcttetgctactccegctac & ATTAACCCTCACTAAAGGGAtagttgttgacccagatcac \\
$r a r$ & gegttacaccaaggtcccaacaacatgtcc & ATTAACCCTCACTAAAGGGAtacatggcatgaagtgttga \\
$r x r$ & gtaaaggtcggcattctcetgaccagtgct & ATTAACCCTCACTAAAGGGAatcagcttgaagaagaagag \\
\hline
\end{tabular}

We used 40-bp reverse primers, including a 20-bp T3 promoter sequence, to synthesize Digoxigenin (Dig)labeled RNA probes for in situ hybridization. Capital letters indicate the consensus sequence for the T3 promoter.

Table A9

Accession numbers for the genes used for phylogenic analysis

\begin{tabular}{|c|c|c|c|c|}
\hline Species & Gene & Accession number & Gene & Accession number \\
\hline \multirow[t]{15}{*}{ Hs, Homo sapiens } & aldhlal & P00352.2 & thra & P10827 \\
\hline & aldh1a2 & O94788 & thrb & P10828 \\
\hline & aldh1a3 & P47895 & rara & P10276 \\
\hline & aldh1b1 & P30837 & rarb & P10826 \\
\hline & aldh2 & P05091 & rarg & P13631 \\
\hline & aldh $3 a 1$ & P30838 & rxra & P19793 \\
\hline & aldh $3 a 2$ & P51648 & $r x r b$ & P28702 \\
\hline & aldh3b1 & P43353 & rxrg & P48443 \\
\hline & aldh3b2 & P48448 & & \\
\hline & aldh4al & P30038 & & \\
\hline & aldh5a1 & P51649 & & \\
\hline & aldh6a1 & Q02252 & & \\
\hline & aldh7a1 & P49419 & & \\
\hline & aldh8a1 & Q9H2A2 & & \\
\hline & aldh9a1 & P49189 & & \\
\hline \multirow{8}{*}{ Mm, Mus musculus } & & & thra & P63058 \\
\hline & & & thrb & P37242 \\
\hline & & & rara & P11416 \\
\hline & & & rarb & P22605 \\
\hline & & & rarg & P18911 \\
\hline & & & rxra & P28700 \\
\hline & & & $r x r b$ & P28704 \\
\hline & & & rxrg & P37238 \\
\hline \multirow[t]{13}{*}{$\mathrm{Xt}$, Xenopus tropicalis } & aldhla1 & Q4VBE1 & & \\
\hline & aldh1a2 & Q9DEX5 & & \\
\hline & aldh1a3 & F7BV06 & & \\
\hline & aldh $1 b 1$ & F7DQF8 & & \\
\hline & aldh2 & Q6DJ49 & & \\
\hline & aldh3a2 & B1WBI3 & & \\
\hline & aldh3b2 & F6X8Y6 & & \\
\hline & aldh4al & A4QNJ0 & & \\
\hline & aldh5a1 & F6QFQ2 & & \\
\hline & aldh6a1 & F6SRL8 & & \\
\hline & aldh7al & F7BQF6 & & \\
\hline & aldh8a1 & F6UH88 & & \\
\hline & aldh9a1 & F6VC33 & & \\
\hline \multirow[t]{8}{*}{ Dr, Danio rerio } & aldh1a2 & Q90XS8 & thraa & Q98867 \\
\hline & aldhla3 & $\mathrm{Q} 0 \mathrm{H} 2 \mathrm{G} 3$ & thrab & U3JAT9 \\
\hline & aldh $2 a$ & Q8QGQ2 & thrb & Q9PVE4 \\
\hline & aldh2b & Q6TH48 & raraa & Q90271 \\
\hline & aldh $3 a 1$ & X1WBM4 & rarab & Q7ZTI3 \\
\hline & aldh $3 a 2 a$ & A0A2R8PW97 & & \\
\hline & aldh $3 a 2 b$ & E9QH31 & rarga & Q91392 \\
\hline & aldh3b1 & Q90ZZ7 & rargb & A2T928 \\
\hline
\end{tabular}


Table A9 (Continued)

\begin{tabular}{|c|c|c|c|c|}
\hline Species & Gene & Accession number & Gene & Accession number \\
\hline & aldh $4 a 1$ & Q7SY23 & & \\
\hline & aldh5a1 & A0A0R4IIB7 & & \\
\hline & aldh6a1 & Q6DHT4 & & \\
\hline & aldh7al & Q803R9 & & \\
\hline & aldh8a1 & Q66I21 & & \\
\hline & aldh9alal & Q7ZVB2 & & \\
\hline & aldh9a1a2 & B0S7W5 & & \\
\hline & aldh9alb & Q802W2 & & \\
\hline \multirow[t]{2}{*}{$\mathrm{Bf}$, Branchiostoma floridae } & aldhla_1 & C3ZGK4 & $r x r$ & Q8MX78 \\
\hline & aldh1a_2 & C3ZG63 & & \\
\hline $\mathrm{Bl}$, Branchiostoma lanceolatum & & & rar & O18608 \\
\hline \multirow[t]{4}{*}{$\mathrm{Ci}$, Ciona intestinalis } & aldh1a_1 & A0A1W2WB51 & rar & Q4H2W1 \\
\hline & aldh1a_2 & A0A1W5BCT1 & $r x r$ & Q4H2U9 \\
\hline & aldh1a_3 & A0A1W2WDC1 & & \\
\hline & aldh2 & A0A1W5B7N8 & & \\
\hline Pm, Polyandrocarpa misakiensis & & & $r x r$ & K7ZLP3 \\
\hline \multirow[t]{6}{*}{ Sk, Saccoglossus kowalevskii } & aldh1a_1 & XP_006823779.1 & rar & XP_002742241.1 \\
\hline & aldh1a_2 & XP_006822197.1 & $r x r$ & D2XNK4 \\
\hline & aldh1a_3 & XP_002736989.1 & & \\
\hline & aldh1a_4 & XP_002731204.1 & & \\
\hline & aldh1a_5 & XP_006824634.1 & & \\
\hline & aldh2 & XP_006816163.1 & & \\
\hline \multirow[t]{9}{*}{ Sp, Strongylocentrotus purpuratus } & aldh2_1 & SPU__007284 & $t h r$ & SPU_025239 \\
\hline & aldh2_2 & SPU_023801 & rar & SPU_016523 \\
\hline & aldh5a1_1 & SPU_007492.1 & $r x r$ & SPU_028422 \\
\hline & aldh5a1_2 & SPU_016767.1 & & \\
\hline & aldh6al & SPU_026493.1 & & \\
\hline & aldh7 & SPU_024895.3a & & \\
\hline & aldh8a1_1 & SPU_017403.1 & & \\
\hline & aldh8a_2 & SPU_000522.1 & & \\
\hline & aldh9 & SPU_002901.3a & & \\
\hline \multirow[t]{4}{*}{$\mathrm{Pp}$, Patiria pectinifera } & raldha & LC379260 & rar & LC379258 \\
\hline & raldhb & LC379261 & $r x r$ & LC379259 \\
\hline & raldhc & LC379262 & $t h r$ & $*$ \\
\hline & aldh2 & * & & \\
\hline \multirow[t]{3}{*}{$\mathrm{Al}$, Astropecten latespinosus } & raldha & LC485972 & rar & LC485975 \\
\hline & raldhb & LC485973 & $r x r$ & LC485976 \\
\hline & raldhc & LC485974 & & \\
\hline Dm, Drosophila melanogaster & & & $u s p$ & P20153 \\
\hline \multirow[t]{2}{*}{$\mathrm{Rc}$, Reishia clavigera } & & & rar & T2HRZ4 \\
\hline & & & $r x r$ & E9RHD8 \\
\hline \multirow[t]{2}{*}{ Ls, Lymnaea stagnalis } & & & rar & D5LIR6 \\
\hline & & & $r x r$ & Q5I7G2 \\
\hline Tc, Tripedalia cystophora & & & $r x r$ & O96562 \\
\hline
\end{tabular}

* Sequences were not deposited to Databank but are available from supplementary datasets 1 or 2 (available online). 